\title{
Closing The Loop: Using Assessment Results To Modify The Curriculum So That Student Quantitative Reasoning Skills Are Enhanced
}

Lynn Johnson, California State University, Stanislaus, USA

\begin{abstract}
Assurance of student learning through effective assessment has become increasingly important over the past decade as accrediting agencies now require documented efforts to measure and improve student performance. This paper presents the methodology used by the College of Business Administration at California State University, Stanislaus to assess its students' quantitative reasoning skills and the resulting actions taken to improve student performance. The critical role that faculty play in developing meaningful assessment instruments and evaluating and acting on the results is emphasized.
\end{abstract}

Keywords: Assessment; Closing the Loop; Quantitative Reasoning

\section{INTRODUCTION}

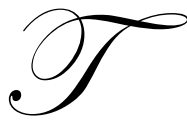

he assessment of student learning has become increasingly important as legislators and policy makers ask for evidence that public monies expended for higher education produce results. Their concerns have resulted in an increased emphasis on direct assessment of student learning outcomes by our accrediting bodies, both regional accreditors and the AACSB. [See chapter two of U.S. Accreditation and the Future of Quality Assurance, by Ewell (2008) for a thorough discussion of the call for increased accountability in higher education.]

I present a direct method of assessment used by business programs in the California State University system, explain how our Business College used the results to identify an area in which student performance was not at the desired level, and identity actions we have taken to improve our students' learning.

\section{INITIAL ASSESSMENT METHODOLOGY}

As the AACSB increasingly expected direct, rather than indirect, assessment measures, those of us in the CSU system charged with coordinating the assessment activities on our individual campuses began to meet periodically to share strategies. One outcome of these meetings was the idea of creating a system-wide business assessment exam to test student knowledge of the core curriculum. This allowed us to control the content of the exam while providing a means of benchmarking our results with those of similar business programs. It also has been much less costly to administer than nationally normed exams.

Faculty within the California State University system developed the Business Assessment Test (know as BAT), which currently consists of eighty multiple-choice questions divided among the following eleven businessrelated topics: accounting, global business perspectives, economics, finance, business law, management, professional ethics, information systems, marketing, production operations management, and statistics. At CSU Stanislaus, we have administered this test each year beginning in 2004-05. We noticed that our students consistently achieved low scores in those areas that require extensive quantitative analysis, such as statistics and finance. While 
student performance in statistics and finance was low across the CSU system (our results were consistent with our benchmarked institutions), our faculty believed it was imperative that we take actions to improve student performance in this area. Professionals have consistently identified numeracy and problem solving skills as essential to success in higher education and the workforce. (for example: Whittle, Pell et. al., 2010; Anonymous, 2011)

\section{Closing the Loop -- Part I}

Weiner (2009) emphasizes that the success of an assessment program depends on having a faculty-led team who plans the program, develops tools for and implements it, and uses the data obtained. Accordingly, at CSU Stanislaus, undergraduate assessment efforts are coordinated by the Undergraduate Assessment Committee, consisting of three members of the business faculty. The committee summarizes the assessment results each year and provides the results to the entire business faculty at an annual Assessment Retreat. The faculty as a whole discusses the results and collectively determines what responsive actions, if any, will be taken. Because our assessment program is entirely faculty-driven and includes all program faculty members in discussions of assessment processes and results, faculty buy-in and interest is relatively high.

The College of Business Administration first attempted to address the weakness in student quantitative skills by working directly with faculty members in the Department of Mathematics to better align our prerequisite math course (Finite Math) with the needs of our program. The Undergraduate Assessment Committee surveyed all members of the business faculty, providing them with a copy of the Finite Math syllabus, and asked them to identify those topics which they considered most important and those that they felt could be eliminated. A group of our faculty then met with several math instructors to review the results of the survey. As a result, the Finite Math course was restructured by eliminating one chapter and increasing the coverage of several critical topics.

\section{REASSESSMENT}

After this change was implemented, we monitored student performance on the BAT. Unfortunately, we did not find any improvement in the students' quantitative skills, as evidenced by their performance on the statistics and finance portions of the test. Faculty members discussed these results at an assessment retreat, during which they considered whether the difficulty might be with more basic arithmetic/algebraic skills than those covered in Finite Math. We all could tell stories about the student who did not know that .01 was one one-hundreth nor realize that the statement: "twice as many apples were sold as oranges" implied a product mix of $2 / 3$ apples and $1 / 3$ oranges. We did not know, however, whether these stories represented a few isolated individuals or whether the problem was more pervasive.

Consequently, the faculty agreed to develop a more closely targeted direct assessment of our students' basic quantitative skills. We first considered whether or not calculators would be allowed. They are not permitted on the BAT; this might partially account for our students' low performance in quantitative areas. The faculty decided that the ability to perform basic math computations without a calculator is an essential skill. Occasions arise in business when professionals need to make quick computations; a calculator may not be immediately available. Business professionals must also be able to estimate the solution to a particular problem so that they can assess the reasonableness of an answer arrived at using electronic aids.

Once again, the Undergraduate Assessment Committee surveyed the faculty and asked them to identify the essential quantitative skills our students need to succeed in our business courses (and in their careers). From the surveys, the committee developed the following list of topics to be covered in our Business Quantitative Skills Assessment Test:

The most important skills identified were the ability to:

- $\quad$ Define the issue in a quantitative word problem

- $\quad$ Evaluate an information set and identify the relevant information

- $\quad$ Develop an equation or model to solve the problem

- $\quad$ Arrive at an appropriate solution. 
In other words, our students must be able to solve basic word problems with irrelevant information included in the data provided.

Other topics identified as important were:

- $\quad$ Simultaneous equations

- $\quad$ Conversion of fractions to decimals and/or percentages, and vice versa.

- Performing arithmetic operations involving fractions, decimals, and percentages without reliance on a calculator.

- $\quad$ Plotting and interpreting graphs

- $\quad$ Ordering decimals (Recognizing that .1 is larger than .021)

- $\quad$ Understanding the place values of the decimal system

- $\quad$ Basic business arithmetic computations such as calculating interest and computing mark-ups.

- $\quad$ Recognizing proportions from a narrative.

- Understanding ratios/proportions.

We developed a thirty question open-ended exam in which each concept was tested at least twice. Three possible outcomes were identified prior to administering the exam:

1. A large majority of students would perform well, telling us that the problems we had noticed were limited to a few students. In this case, no action would be necessary.

2. A significant number of students would fail to understand a few key concepts. If this proved to be true, we planned to develop a series of single-topic workshops. Students would be directed into the ones that covered the topics on which they scored poorly.

3. A significant number of students would perform poorly overall. In this situation, we planned to develop a two-unit course in business quantitative analysis.

During 2010-11, the test was administered to 124 of our students at the beginning of their junior year. The median and average score was $53 \%$ overall, considerably below the $70 \%$ we had established as the target score. We found that almost all of our students are able to order decimals, understand the place values of the decimal system, and can locate points on a graph; the majority can also convert fractions, decimals, and percentages. However, student performance on all the other skills tested was lower than desired. They particularly require improvement of the skills identified by faculty as most important to their future success: the ability to identify a problem, evaluate an information set, determine what information is relevant to the problem, set up an equation to solve the problem, and arrive at an appropriate solution.

\section{Closing the Loop -- Part II}

In response to the assessment results, the College of Business Administration has developed a course titled "Elementary Business Quantitative Analysis" (BUS 103). This course has four primary student learning objectives identified in the syllabus:

Students will be able to:

1. Define the issue in a quantitative business problem.

2. Discriminate between relevant and irrelevant information when presented with quantitative business problems.

3. Develop appropriate models to solve quantitative business problems.

4. Transfer quantitative concepts across problems and contexts.

As students develop models that allow them to solve various business problems, basic arithmetic and algebraic concepts will be reviewed. We added the fourth learning objective to our set of essential skills because this skill is critical to the development of sophisticated quantitative reasoning. Jordan and Haines (2003) define 
quantitative reasoning as "the ability to select, apply, and explain a variety of quantitative methods across different contexts. " Students will gain experience recognizing when a particular quantitative model is appropriate. For example, the use of weighted averages arises in a number of contexts in business: students will learn to identify when use of this basic computational model is appropriate and apply the model correctly. Since we are concerned with developing skills, rather than with specific content, instructors may vary in their choice of business applications with which to provide students practice in skill development and transfer.

We converted the Business Quantitative Skills Assessment Test (BQSAT) into a multiple-choice format, using student responses to the previously administered open-ended exam to develop incorrect question stems. We are adding the following prerequisite to our quantitative business classes: BUS 103 or a minimum score of $70 \%$ on the BQSAT. This requirement is expected to be implemented next year. After it is in place for two years, we will again review the BAT results to help us determine the effectiveness of this curricular change.

\section{CONCLUSION}

While the College of Business Administration at CSU Stanislaus has not yet determined whether the curricular changes made to improve student quantitative skills are effective, the faculty has found the assessment process itself to be of significant benefit. Assessment in our program is entirely faculty driven. While the Dean and Provost's office provide financial support in the form of assigned time for the chair of the Undergraduate Assessment Committee ( 3 to 5 semester teaching units annually) and small stipends to faculty members who complete assessment tasks during the summer, responsibility for development of the assessment plan, collection and analysis of data, and determination of responsive actions resides with the faculty. Faculty ownership of the process, including the involvement of all faculty members in decision-making, is transforming our assessment practices from being primarily compliance-based (undertaken only to satisfy accrediting bodies) to being truly learning-centered. Faculty members are able to tailor the assessment instruments to address the skills and knowledge that they consider to be most important. Because they are involved in the instrument's development, interest in the results is high and thoughtful conversations about the curriculum ensue.

\section{AUTHOR INFORMATION}

Lynn Johnson is a Professor of Accounting at CSU Stanislaus, teaching Auditing and Intermediate Accounting. She has coordinated undergraduate assessment in the College of Business Administration since 2003. She has published articles in Accounting Forum and New Accountant, primarily in the area of audit pricing and production costs. E-mail: Ljohnson3@csustan.edu

\section{REFERENCES}

1. Anonymous, 2011. A View From the Bridge: What Pupils Are Missing: Analysis. The Times Educational Supplement 4948 (July 1, 2011): 26.

2. Ewell, P., 2008. U.S. Accreditation and the Future of Quality Assurance. Washington, D.C., Council for Higher Education Accreditation.

3. Jordan, J. and B. Haines, 2003. Fostering Quantitative Literacy, Peer Review 5(4): 16 - 19.

4. Weiner, W., 2009. Establishing a Culture of Assessment, Academe 95(4).

5. Whittle, S., Pell, G. and Murdoch-Eaton, D. Recent Changes to Students' Perceptions of Their Key Skills on Entry to Higher Education, Journal of Further and Higher Education 34(4): 557 - 570. 